Free base tetraazaporphine isolated in inert gas hosts: Matrix influence on its spectroscopic and photochemical properties

Chris Henchy, John G. McCaffrey', Serguei Arabei, Tatiana Pavich, Jean-Pierre Galaup, Niloufar Shafizadeh, and Claudine Crépin'

Citation: J. Chem. Phys. 141, 124303 (2014); doi: 10.1063/1.4894761

View online: http://dx.doi.org/10.1063/1.4894761

View Table of Contents: http://aip.scitation.org/toc/jcp/141/12

Published by the American Institute of Physics 


\title{
Free base tetraazaporphine isolated in inert gas hosts: Matrix influence on its spectroscopic and photochemical properties
}

\author{
Chris Henchy, ${ }^{1}$ John G. McCaffrey, ${ }^{1, \text { a) }}$ Serguei Arabei, ${ }^{2}$ Tatiana Pavich, ${ }^{3}$ \\ Jean-Pierre Galaup, ${ }^{4}$ Niloufar Shafizadeh, ${ }^{5}$ and Claudine Crépin ${ }^{5, b)}$ \\ ${ }^{1}$ Department of Chemistry, National University of Ireland - Maynooth, Maynooth, County Kildare, Ireland \\ ${ }^{2}$ Department of Chemistry, Belarussian State Agrarian Technical University, Minsk, Belarus \\ ${ }^{3}$ B.I. Stepanov Institute of Physics, Minsk, Belarus \\ ${ }^{4}$ Laboratoire Aimé Cotton, UPR3321 CNRS - Université Paris-Sud 11, F-91405 Orsay, France \\ ${ }^{5}$ Institut des Sciences Moléculaires d'Orsay, UMR8214 CNRS - Université Paris-Sud 11, \\ F-91405 Orsay, France
}

(Received 7 July 2014; accepted 25 August 2014; published online 23 September 2014)

\begin{abstract}
The absorption, fluorescence, and excitation spectra of free base tetraazaporphine $\left(\mathrm{H}_{2} \mathrm{TAP}\right)$ trapped in $\mathrm{Ne}, \mathrm{N}_{2}$, and Ar matrices have been recorded at cryogenic temperatures. Normal Raman spectra of $\mathrm{H}_{2}$ TAP were recorded in $\mathrm{KBr}$ discs and predicted with density functional theory (DFT) using large basis sets calculations. The vibrational frequencies observed in the Raman Spectrum exhibit reasonable agreement with those deduced from the emission spectra, as well as with frequencies predicted from large basis set DFT computations. The upper state vibrational frequencies, obtained from highly resolved, site selected excitation spectra, are consistently lower than the ground state frequencies. This contrasts with the situation in free base phthalocyanine, where the upper state shows little changes in vibrational frequencies and geometry when compared with the ground state. Investigations of the photochemical properties of $\mathrm{H}_{2}$ TAP isolated in the three matrices have been performed using the method of persistent spectral hole-burning (PSHB). This technique has been used to reveal sites corresponding to distinct $\mathrm{N}-\mathrm{H}$ tautomers which were not evident in the absorption spectra. An analysis of the holes and antiholes produced with PSHB in the $\mathrm{Q}_{\mathrm{x}}(0-0)$ absorption band made it possible to identify inter-conversion of distinct host sites. () 2014 AIP Publishing LLC. [http://dx.doi.org/10.1063/1.4894761]
\end{abstract}

\section{INTRODUCTION}

Considering that the porphyrins (Ps) are responsible for most of the colours that exist in nature and phthalocyanines (Pcs) find widespread use as dye materials in industry, it is to be expected that these two vitally important families of molecules continue to be the subjects of active research. The Pcs are synthetic derivatives of Ps in which nitrogen atoms at the meso position in the aromatic polyene ring connect the four pyrrole groups in Pcs instead of the bridgingcarbon atoms in Ps. The essential optical difference between the two families of molecules is that the Pcs absorb very strongly in the red portion of the visible spectrum while the Ps absorb more weakly there. For this reason and their very high stability, the Pcs were originally used as dyes, ${ }^{1}$ but more recently have found targeted use in applications such as photoconductors, ${ }^{2}$ as nonlinear optical materials ${ }^{3}$ or as photosensitisers in laser cancer therapy. ${ }^{4}$ The parent molecule of the phthalocyanine family is free base tetraazaporphine $\left(\mathrm{H}_{2} \mathrm{TAP}\right)$ $\left(\mathrm{C}_{16} \mathrm{H}_{10} \mathrm{~N}_{8}\right)$ whose structure is shown in Fig. 1. Depending on the positions of the two hydrogen atoms, which can migrate between the four nitrogen atoms in the inner cavity, $\mathrm{H}_{2}$ TAP has two stable tautomers when isolated in low temperature solids. We decided to investigate the spectroscopy of $\mathrm{H}_{2}$ TAP

\footnotetext{
a)Email: john.mccaffrey@nuim.ie

b) Email: claudine.crepin-gilbert@u-psud.fr
}

in cryogenic solids as these media provide a convenient inert environment to conduct resolved vibrational spectroscopy. The host used interacts only weakly with the guest species, and one can expect the frequencies obtained from the $\mathrm{H}_{2}$ TAP spectra to be close to their gas phase values, which are currently not known.

In contrast to free base porphine $\left(\mathrm{H}_{2} \mathrm{P}\right)$, the transition between the ground state $S_{0}(G)$ and the first excited singlet state $\mathrm{S}_{1}$ is fully allowed in $\mathrm{H}_{2}$ TAP. This transition is responsible for the intense, so-called "quasi" (Q) band absorptions in the red part of the spectrum. ${ }^{5}$ In the first excited singlet $S_{1}$ state of the free base molecules $\left(\mathrm{H}_{2} \mathrm{P}\right.$ and $\mathrm{H}_{2} \mathrm{TAP}$ - both with $\mathrm{D}_{2 \mathrm{~h}}$ symmetry) the degeneracy of the $\mathrm{D}_{4 \mathrm{~h}}$ metal tetrapyrroles is lifted and two distinct states arise-namely, the $\mathrm{Q}_{\mathrm{x}}\left(\mathrm{S}_{1}\right)$ at lower energy and the $\mathrm{Q}_{\mathrm{y}}\left(\mathrm{S}_{2}\right)$ at higher energy. In chlorobenzene solution at room temperature, the $\mathrm{Q}_{\mathrm{x}}$ band of $\mathrm{H}_{2}$ TAP absorbs in the region of $617 \mathrm{~nm}$ with the $\mathrm{Q}_{\mathrm{y}}$ band located at $545 \mathrm{~nm}$. As indicated in Table I, a pronounced blueshift to $614 \mathrm{~nm}$ occurs on the $Q_{x}$ band when n-octane is used as a solvent.

In recent work $^{6}$ we studied the optical properties of free base phthalocyanine $\left(\mathrm{H}_{2} \mathrm{Pc}\right)$ and zinc phthalocyanine $(\mathrm{ZnPc})$ isolated in low temperature matrices building on existing work in a wide range of different environments. The phthalocyanines have been examined in the solid state, ${ }^{7-11}$ in the gas phase, ${ }^{12-14}$ free expansions, ${ }^{15,16}$ and in helium droplets. ${ }^{17,18}$ In contrast, high resolution spectroscopy of the parent molecule $\mathrm{H}_{2}$ TAP appears to have only been studied in 


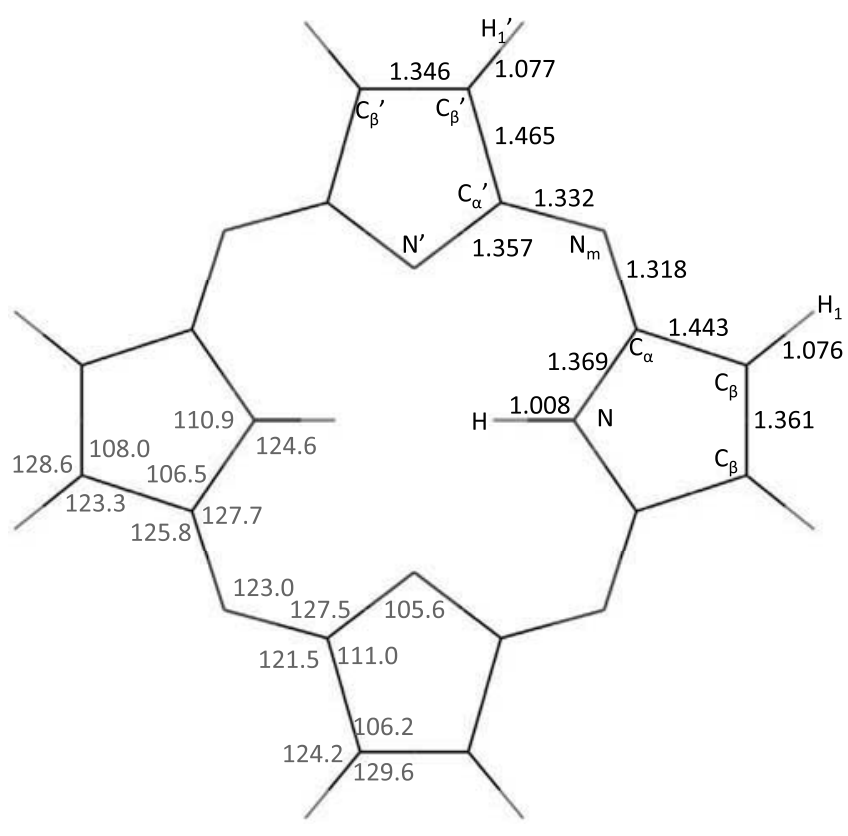

FIG. 1. The ground state structure of $\mathrm{H}_{2}$ TAP determined by DFT geometry optimisation using the B3LYP functional and the $3 d f, 3 p d$ basis set. The unique bond lengths are presented on the upper right in A units while the angles are given in degrees on the lower left. The structure is planar having $\mathrm{D}_{2 \mathrm{~h}}$ symmetry.

Shpol'skii organic matrices ${ }^{19-22}$ where large $\left(\sim 53 \mathrm{~cm}^{-1}\right)$ siteinduced tautomeric splitting complicates the analysis of the fluorescence spectra. However, when excitation spectra were recorded by monitoring site-specific emission, quasi-line "absorption" spectra were obtained. ${ }^{19}$ In Ref. 19 , the spectra were reported to about $20400 \mathrm{~cm}^{-1}$. They show resolved lines, but above $18500 \mathrm{~cm}^{-1}$ very complex bands appear. This congested region, centred around $18600 \mathrm{~cm}^{-1}$ is the location of the $\mathrm{Q}_{\mathrm{y}}\left(\mathrm{S}_{2}\right)$ state origin, with the complexity arising from coupling ${ }^{20,22}$ with the vibrational levels of the $Q_{x}\left(S_{1}\right)$ state. Since no fundamental vibrational modes of the $Q_{x}$ state of $\mathrm{H}_{2}$ TAP lie in the region, this coupling must involve overtone or combination bands.

In this paper we present the results of a study of the absorption and fluorescence spectra of $\mathrm{H}_{2}$ TAP isolated in rare gas and nitrogen matrices in the region of the $\mathrm{Q}$ bands. Excita- tions of both the $\mathrm{Q}_{\mathrm{x}}$ and the $\mathrm{Q}_{\mathrm{y}}$ states were used to produce the reported emission. In addition, normal Raman spectroscopy has been recorded and predicted by high level density functional theory (DFT) calculations. A key aspect of the present work is the exploitation of the ground state Raman results in providing assignments of the observed emission bands. Analysis of the recorded fluorescence excitation spectra and observed hole-burning is also presented to probe aspects of site occupancy and $\mathrm{N}-\mathrm{H}$ tautomerism.

\section{METHODS}

\section{A. Experimental}

Experiments on $\mathrm{H}_{2}$ TAP were undertaken at the Institut des Sciences Moléculaires d'Orsay (ISMO) while calculations were conducted by the Low Temperature Spectroscopy (LTS) group at NUI-Maynooth. $\mathrm{H}_{2}$ TAP was provided by the Minsk group utilising the synthetic method of Makarova et $a l .{ }^{23}$. The cryostat, described in Ref. 24, was cooled by a closed cycle helium refrigerator (displex) which allowed a lowest temperature of $7 \mathrm{~K}$, but in the present work was operated mostly at $8 \mathrm{~K}$. A resistively heated custom built oven described previously ${ }^{25,26}$ was used to heat and sublime the $\mathrm{H}_{2}$ TAP powder to about $190^{\circ} \mathrm{C}$. The resulting vapour was entrained for deposition on a sapphire window in a large excess of the matrix gas $(40 \mathrm{mmol} / \mathrm{h})$ to isolate the $\mathrm{H}_{2}$ TAP as monomer. Ne samples were deposited at $8 \mathrm{~K}$, while $20 \mathrm{~K}$ was used for both $\mathrm{Ar}$ and $\mathrm{N}_{2}$ samples. These high deposition temperatures were used to reduce multiple site occupancy of this large molecule. Further annealing was not undertaken. The isolation condition of $\mathrm{H}_{2}$ TAP in the matrix samples was monitored with absorption spectroscopy of the $\mathrm{Q}_{\mathrm{x}}$ band origin, around $600 \mathrm{~nm}$.

Absorption spectra were recorded with a $0.6 \mathrm{~m}$ JobinYvon monochromator having a resolution of few $\mathrm{cm}^{-1}$ using a tungsten lamp as the light source. Emission was produced with tuneable dye laser excitation using two lasers to cover the spectral range 500-610 nm. For the longer wavelength region, DCM dye was pumped by the second harmonic of a Quantel Q-switched Nd:YAG laser which has been described ${ }^{24}$ previously. Shorter wavelengths were generated using Coumarin 540 in a Lambda Physik LPD3000 dye laser

TABLE I. Absorption wavelength and wavenumber $\left(\mathrm{nm} / \mathrm{cm}^{-1}\right)$ values for the $(0-0)$ transition of $\mathrm{H}_{2} T A P\left(Q_{x}\right.$ and $Q_{y}$ bands) in different materials. In solids where doublet splitting is present, the red component has been selected in all cases.

\begin{tabular}{|c|c|c|c|c|c|c|c|}
\hline \multirow{2}{*}{\multicolumn{2}{|c|}{ Environment }} & \multirow[b]{2}{*}{ Temp. (K) } & \multicolumn{2}{|c|}{$\mathrm{Q}_{\mathrm{x}}$} & \multicolumn{2}{|c|}{$\mathrm{Q}_{\mathrm{y}}$} & \multirow[b]{2}{*}{$\Delta \mathrm{E}\left(\mathrm{Q}_{\mathrm{y}}-\mathrm{Q}_{\mathrm{x}}\right)\left(\mathrm{cm}^{-1}\right)$} \\
\hline & & & $\lambda(\mathrm{nm})$ & $\mathrm{E}\left(\mathrm{cm}^{-1}\right)$ & $\lambda(\mathrm{nm})$ & $\mathrm{E}\left(\mathrm{cm}^{-1}\right)$ & \\
\hline \multirow[t]{3}{*}{ Solution } & Chloroform ${ }^{23}$ & 300 & 619 & 16155 & 547 & 18280 & 2125 \\
\hline & Chloro-benzene $\mathrm{e}^{5}$ & 300 & 617 & 16210 & 545 & 18350 & 2140 \\
\hline & n-Octane $e^{20}$ & 300 & 614 & 16305 & 536 & 18640 & 2335 \\
\hline \multirow[t]{5}{*}{ Solid matrix } & n-Octane (Shpol'skii) ${ }^{22}$ & 4.2 & 611.5 & 16353 & 538.0 & 18587 & 2234 \\
\hline & & & 613.5 & 16300 & 537.1 & 18619 & 2319 \\
\hline & $\mathrm{Ne}$ & 8 & 600.5 & 16653 & 520.5 & 19211 & 2558 \\
\hline & $\mathrm{N}_{2}$ & 8 & 603.3 & 16575 & 528.4 & 18925 & 2350 \\
\hline & $\mathrm{Ar}$ & 8 & 604.9 & 16534 & 526.8 & 18982 & 2448 \\
\hline
\end{tabular}


pumped by the output of a Lumonics PM-886 XeCl excimer laser. Emission spectra were recorded using a time-gated, iCCD camera for photon detection (Andor DH720 system). The wavelength positions of the spectra reported were obtained by calibration of the monochromator with a mercury lamp. With the absolute position of the monochromator established, the wavelength of the dye laser was obtained for each excitation scan by finding the laser position in the CCD scans with the same monochromator. Excited state lifetimes were extracted from the time-resolved emission spectra by fitting the extracted decay curves with single exponential functions. Excitation spectra were recorded by scanning the dye laser while monitoring a range of emission wavelengths with the camera. This technique allowed us to record high-resolution excitation spectra of several emission bands simultaneously. The resulting 2D excitation-emission matrix (EEM) plots provide a very powerful method of analysing complex absorption spectra arising from multiple site occupancy. All the excitation spectra shown were obtained by monitoring selected pixels in the series of CCD emission spectra recorded. The bandwidth of the emission monochromator is around $3 \mathrm{~cm}^{-1}$ while the linewidth of the dye laser is less than $1 \mathrm{~cm}^{-1}$. No correction, including the spectral sensitivity of the detection system, was applied to the spectral data. Conventional Raman spectra were recorded for $\mathrm{H}_{2} \mathrm{TAP}$ in $\mathrm{KBr}$ discs on a JY-Horiba LabRAM HR spectrometer at the "Fócas" research facility, DIT, Dublin. The $532 \mathrm{~nm}$ laser line was used as the light source and accumulation times were typically $20 \mathrm{~min}$.

Persistent spectral hole-burning (PSHB) was performed on the $\mathrm{Q}_{\mathrm{x}}(0-0)$ absorption band of $\mathrm{H}_{2} \mathrm{TAP}$ in $\mathrm{Ar}, \mathrm{N}_{2}$, and $\mathrm{Ne}$ matrices at temperatures of $8 \mathrm{~K}$. The laser intensity used in the experiments for the creation of holes was $1-10 \mathrm{~mW}$ which corresponds to a power density of between 4 and $40 \mathrm{~mW} / \mathrm{cm}^{2}$. Spectral holes were recorded using the sample transmittance, which were then converted to optical density (OD). The spectral holes presented were obtained by subtracting the initial spectrum from that recorded after hole-burning.

\section{B. Theoretical}

DFT was used with the B3LYP functional for both geometry optimisation and the calculation of vibrational frequencies. This is currently the most effective theoretical method for obtaining ground state molecular vibrational frequencies. Moreover, as established in our previous study ${ }^{27}$ of zinc and free base phthalocyanine, the Raman intensities are also reliable. A variety of basis sets were utilised during the course of this work - specifically the 6-31g $(d), 6-311 \mathrm{G}++(2 d, 2 p)$, and $6-311 \mathrm{G}++(3 d f, 3 p d)-$ but only the results of the largest one are utilised in this work. The smallest one was compared with the DFT results published a decade ago by Berezin et $a .^{28}$ using the same basis set. All of the present calculations were conducted with the Gaussian 03 suite of programmes $^{29}$ running, as described in Ref. 30, on a Linux workstation with two quad-core processors. When comparing with experimental results, the calculated vibrational frequencies were scaled by a uniform factor of 0.98 , unless stated otherwise.

\section{RESULTS AND DISCUSSION}

\section{A. DFT calculations}

DFT was used for geometry optimisation of $\mathrm{H}_{2}$ TAP and to calculate the ground state vibrational frequencies. No imaginary frequencies were found for any vibrational mode from which we conclude that the most stable molecular geometry is indeed planar, with $D_{2 h}$ symmetry. The unique bond lengths and bond angles of $\mathrm{H}_{2}$ TAP determined using the specified basis sets are collected in Table II, while the values obtained with the largest $[6-31 \mathrm{G}(3 d f, 3 p d)]$ basis set are indicated on the molecular structure shown in Fig. 1. It is noteworthy in Table II that the bond lengths obtained with the smallest basis set $[6-31 \mathrm{~g}(d)]$ calculation are considerably longer than those obtained with the two larger ones. In addition, the values obtained with larger basis sets differ very little from one another. From this we conclude that the larger basis sets are appropriate for geometry optimisation and the prediction of vibrational spectra. Looking at the results of the largest basis set calculation, it is evident that the lengths of the 16 bonds $(\mathrm{C}-\mathrm{N}$ and $\mathrm{C}-\mathrm{C})$ in the tetrapyrrole ring are all quite similar - in the region of $1.3 \AA$ - with values ranging only from 1.32 to $1.37 \AA$. This similarity in the bond lengths is an

TABLE II. Geometric parameters determined for ground state $\mathrm{H}_{2}$ TAP by the DFT method at three levels of theory. See Fig. 1 for the atom labelling used.

\begin{tabular}{|c|c|c|c|}
\hline \multirow[b]{2}{*}{ Length $(\AA)$} & \multirow{2}{*}{$\frac{6-31 g}{D}$} & \multicolumn{2}{|c|}{$6-311++g$} \\
\hline & & $2 d, 2 p$ & $3 d f, 3 p d$ \\
\hline $\mathrm{N}-\mathrm{H}$ & 1.0125 & 1.0076 & 1.0080 \\
\hline $\mathrm{N}-\mathrm{C}_{\alpha}$ & 1.3738 & 1.3701 & 1.3686 \\
\hline $\mathrm{C}_{\alpha}-\mathrm{Nm}$ & 1.3236 & 1.3195 & 1.3179 \\
\hline $\mathrm{C}_{\alpha}-\mathrm{C}_{\beta}$ & 1.4467 & 1.4436 & 1.4426 \\
\hline $\mathrm{C}_{\beta}-\mathrm{C}_{\beta}$ & 1.3664 & 1.3616 & 1.3607 \\
\hline $\mathrm{C}_{\beta}-\mathrm{H}_{1}$ & 1.0809 & 1.0759 & 1.0762 \\
\hline $\mathrm{N}^{\prime}-\mathrm{C}_{\alpha}{ }^{\prime}$ & 1.363 & 1.3593 & 1.3573 \\
\hline $\mathrm{C} \alpha^{\prime}-\mathrm{N}_{\mathrm{m}}$ & 1.3375 & 1.3338 & 1.3321 \\
\hline $\mathrm{C}_{\alpha}{ }^{\prime}-\mathrm{C}_{\beta}{ }^{\prime}$ & 1.4687 & 1.4657 & 1.4650 \\
\hline $\mathrm{C}_{\beta}{ }^{\prime}-\mathrm{C}_{\beta}^{\prime}{ }^{\prime}$ & 1.3517 & 1.3466 & 1.3458 \\
\hline $\mathrm{C}_{\beta}{ }^{\prime}-\mathrm{H}_{1}^{\prime}$ & 1.0816 & 1.0766 & 1.0769 \\
\hline \multicolumn{4}{|l|}{ Angle (deg) } \\
\hline $\mathrm{H}-\mathrm{N}-\mathrm{C}_{\alpha}$ & 124.57 & 124.59 & 124.56 \\
\hline $\mathrm{N}-\mathrm{C}_{\alpha}-\mathrm{N}_{\mathrm{m}}$ & 127.87 & 127.75 & 127.67 \\
\hline $\mathrm{C}_{\alpha}-\mathrm{N}-\mathrm{C}_{\alpha}$ & 110.86 & 110.81 & 110.88 \\
\hline $\mathrm{C}_{\alpha}-\mathrm{N}_{\mathrm{m}}-\mathrm{C}_{\alpha}$ & 122.55 & 122.86 & 123.03 \\
\hline $\mathrm{N}-\mathrm{C}_{\alpha}-\mathrm{C}_{\beta}$ & 106.53 & 106.55 & 106.52 \\
\hline $\mathrm{C}_{\alpha}-\mathrm{C}_{\beta}-\mathrm{C}_{\beta}$ & 108.04 & 108.04 & 108.04 \\
\hline $\mathrm{C}_{\alpha}-\mathrm{C}_{\beta}-\mathrm{H}_{1}$ & 123.22 & 123.34 & 123.33 \\
\hline $\mathrm{C}_{\beta}-\mathrm{C}_{\beta}-\mathrm{H}_{1}$ & 128.74 & 128.62 & 128.63 \\
\hline $\mathrm{N}_{\mathrm{m}}-\mathrm{C}_{\alpha}-\mathrm{C}_{\beta}$ & 125.78 & 125.70 & 125.80 \\
\hline $\mathrm{N}^{\prime}-\mathrm{C}_{\alpha}{ }^{\prime}-\mathrm{N}_{\mathrm{m}}$ & 127.64 & 127.56 & 127.55 \\
\hline $\mathrm{C}_{\alpha}{ }^{\prime}-\mathrm{N}^{\prime}-\mathrm{C}_{\alpha}{ }^{\prime}$ & 105.27 & 105.53 & 105.62 \\
\hline $\mathrm{N}^{\prime}-\mathrm{C}_{\alpha}{ }^{\prime}-\mathrm{C}_{\beta}^{\prime}{ }^{\prime}$ & 111.25 & 111.04 & 111.00 \\
\hline $\mathrm{C}_{\alpha}{ }^{\prime}-\mathrm{C}_{\beta}{ }^{\prime}-\mathrm{C}_{\beta}{ }^{\prime}$ & 106.11 & 106.20 & 106.19 \\
\hline $\mathrm{C}_{\alpha}{ }^{\prime}-\mathrm{C}_{\beta}{ }^{\prime}-\mathrm{H}_{2}$ & 124.13 & 124.24 & 124.23 \\
\hline $\mathrm{C}_{\beta}{ }^{\prime}-\mathrm{C}_{\beta}^{\prime}{ }^{\prime}-\mathrm{H}_{2}$ & 129.77 & 129.57 & 129.59 \\
\hline $\mathrm{N}_{\mathrm{m}}-\mathrm{C}_{\alpha}{ }^{\prime}-\mathrm{C}_{\beta}{ }^{\prime}$ & 121.10 & 121.40 & 121.45 \\
\hline
\end{tabular}


TABLE III. Harmonic vibrational frequencies and intensities of the 48 Raman-active normal modes of $\mathrm{H}_{2}$ TAP predicted by DFT calculation using the $3 d f, 3 p d$ basis set.

\begin{tabular}{|c|c|c|c|c|c|c|c|}
\hline Sym. & Mode \# & $\begin{array}{c}\text { Frequency } \\
\quad\left(\mathrm{cm}^{-1}\right)\end{array}$ & $\begin{array}{l}\text { Intensity } \\
\left(\AA^{4} / \mathrm{amu}\right)\end{array}$ & Sym. & Mode \# & $\begin{array}{c}\text { Frequency } \\
\left(\mathrm{cm}^{-1}\right)\end{array}$ & $\begin{array}{l}\text { Intensity } \\
\left(\AA^{4} / \mathrm{amu}\right)\end{array}$ \\
\hline \multirow[t]{17}{*}{$A_{g}$} & 7 & 181.3 & 33.3 & \multirow[t]{8}{*}{$\mathrm{B}_{2 \mathrm{~g}}$} & 4 & 101.9 & 1.1 \\
\hline & 12 & 337.9 & 84.8 & & 8 & 193.7 & 0.1 \\
\hline & 27 & 704.5 & 14.5 & & 18 & 439.3 & 0.6 \\
\hline & 32 & 744.4 & 90.8 & & 23 & 651.7 & 1.4 \\
\hline & 52 & 971.1 & 115.8 & & 26 & 688.6 & 2.0 \\
\hline & 54 & 1003.8 & 126.5 & & 34 & 756.1 & 1.2 \\
\hline & 59 & 1074.5 & 5.2 & & 43 & 827.3 & 0.0 \\
\hline & 60 & 1079.1 & 63.5 & & 47 & 950.1 & 0.3 \\
\hline & 69 & 1330.2 & 1009.1 & \multirow[t]{16}{*}{$\mathrm{B}_{1 \mathrm{~g}}$} & 6 & 139.3 & 10.5 \\
\hline & 74 & 1423.1 & 57.4 & & 19 & 439.5 & 7.2 \\
\hline & 77 & 1478.9 & 176.2 & & 20 & 453.6 & 0.0 \\
\hline & 80 & 1538.5 & 1396.5 & & 39 & 777.7 & 1.3 \\
\hline & 84 & 1581.0 & 846.1 & & 40 & 805.9 & 4.2 \\
\hline & 86 & 1602.5 & 394.5 & & 50 & 954.1 & 15.7 \\
\hline & 92 & 3259.6 & 612.4 & & 56 & 1016.7 & 12.1 \\
\hline & 94 & 3267.0 & 619.9 & & 62 & 1166.9 & 2.9 \\
\hline & 96 & 3624.3 & 5.6 & & 64 & 1216.9 & 16.7 \\
\hline \multirow[t]{7}{*}{$B_{3 g}$} & 5 & 122.2 & 0.8 & & 65 & 1253.9 & 0.1 \\
\hline & 10 & 218.4 & 0.4 & & 70 & 1333.1 & 0.2 \\
\hline & 21 & 463.4 & 0.4 & & 72 & 1362.6 & 0.7 \\
\hline & 25 & 686.2 & 2.2 & & 76 & 1474.3 & 13.3 \\
\hline & 31 & 742.3 & 2.0 & & 83 & 1571.1 & 8.2 \\
\hline & 42 & 825.0 & 1.0 & & 87 & 3239.8 & 237.6 \\
\hline & 46 & 949.3 & 0.0 & & 90 & 3250.8 & 257.4 \\
\hline
\end{tabular}

indication of the strength of the conjugation on the inner ring and the extent of $\pi$-electron delocalisation occurring there. As far as we are aware, no crystal structures have yet been determined for $\mathrm{H}_{2}$ TAP for comparison with the present calculated values.

The frequencies and intensities predicted by DFT with the largest basis set for all 48 fundamental Raman-active modes of $\mathrm{H}_{2}$ TAP are provided in Table III. It should be noted that the symmetry labelling used in this table has the principal (z) axis perpendicular to the molecular plane rather than passing through the two $\mathrm{N}-\mathrm{H}$ bonds as IUPAC convention recommends and Gaussian 03 implements. This change in axis system has the effect of interchanging the 1 and 3 subscripts on the B irreducible representations. It was done to allow direct comparison with existing literature and future work on metal TAP molecules.

While $\mathrm{H}_{2}$ TAP is the smallest of the free base tetrapyrrole molecules, containing 34 atoms -4 fewer than its closest relation, free base porphyrin $\left(\mathrm{H}_{2} \mathrm{P}\right.$, porphine $)$ - it still produces 96 normal modes of vibration. However, due to the high $D_{2 h}$ symmetry found in the DFT calculations, the 96 vibrations are classified as follows into eight symmetry blocks: $17 \mathrm{~A}_{\mathrm{g}}(\mathrm{R})$, $7 \mathrm{~A}_{\mathrm{u}}, 16 \mathrm{~B}_{1 \mathrm{~g}}(\mathrm{R}), 9 \mathrm{~B}_{1 \mathrm{u}}(\mathrm{IR}), 8 \mathrm{~B}_{2 \mathrm{~g}}(\mathrm{R}), 16 \mathrm{~B}_{2 \mathrm{u}}(\mathrm{IR}), 7 \mathrm{~B}_{3 \mathrm{~g}}(\mathrm{R})$, and $16 B_{3 u}(I R)$ where IR indicates infrared-active modes and $R$, Raman-active modes. Because this molecule has a centre of inversion, mutual exclusion occurs between the IR-active and the Raman-active modes. As a result, only the $\mathrm{A}_{\mathrm{g}}, \mathrm{B}_{1 \mathrm{~g}}, \mathrm{~B}_{2 \mathrm{~g}}$, and $\mathrm{B}_{3 \mathrm{~g}}$ modes from the above list are expected in the Raman spectra.

\section{B. Raman spectra}

The normal Raman spectrum of $\mathrm{H}_{2} \mathrm{TAP}$, recorded in $\mathrm{KBr}$ discs with $532 \mathrm{~nm} \mathrm{CW}$ laser excitation, is shown by the blue trace in Fig. 2. The red trace in the plot is the Raman spectrum predicted by the highest level DFT calculation mentioned above. For the purposes of comparison with experimental data, the band frequencies of the DFT spectrum are scaled uniformly by 0.98 . The observed and predicted spectra

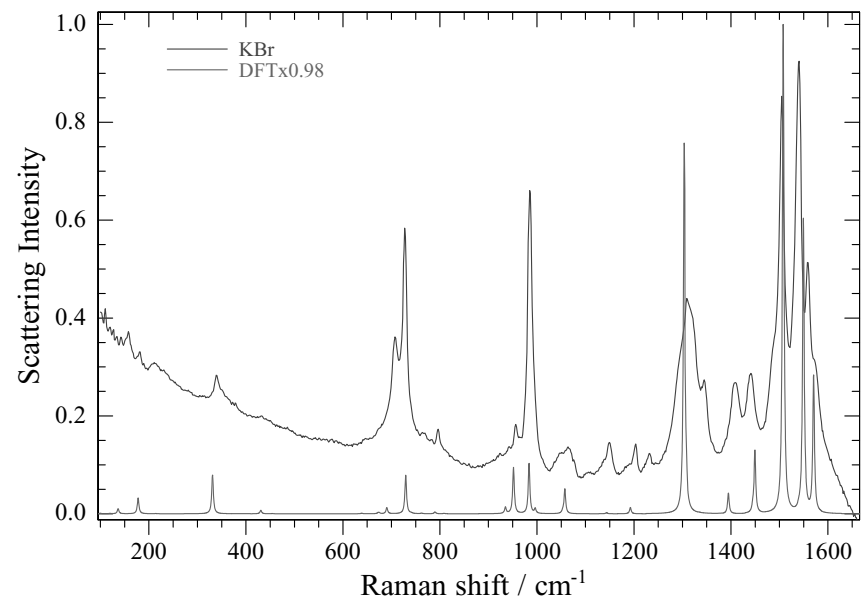

FIG. 2. A comparison of the recorded Raman spectrum of $\mathrm{H}_{2}$ TAP (in red) with that predicted by DFT calculation (blue trace). The calculated spectrum is scaled uniformly by a factor of 0.98 , while a bandwidth of $2 \mathrm{~cm}^{-1}$ was used in generating the simulated lineshapes. 
TABLE IV. Vibrational frequencies $\left(\mathrm{cm}^{-1}\right)$ of $\mathrm{H}_{2}$ TAP extracted from the recorded emission spectra of the molecule isolated in $\mathrm{N}_{2}, \mathrm{Ne}, \mathrm{Ar},(8 \mathrm{~K})$ and Shpol'skii matrices $(5 \mathrm{~K})$. The Shpol'skii values shown in italic correspond to additional observed bands at $77 \mathrm{~K}$. These values are compared with Raman data both experimental and predicted by DFT calculation. The values shown in bold font are the most intense features in the DFT predicted spectrum.

\begin{tabular}{|c|c|c|c|c|c|c|}
\hline \multicolumn{3}{|c|}{ Raman } & \multicolumn{4}{|c|}{ Emission } \\
\hline DFT $(\times 0.98)$ & Mode symmetry & $\mathrm{KBr}$ & $\mathrm{N}_{2}$ & $\mathrm{Ne}$ & $\mathrm{Ar}$ & Shpol'skii Huang, ${ }^{19}$ Gladkov ${ }^{21}$ \\
\hline 136.5 & $B_{1 \mathrm{~g}}$ & 158 & & & & \\
\hline 177.7 & $A_{g}$ & 181 & & 181 & & 181 \\
\hline 331.2 & $A_{g}$ & 340 & 333 & 336 & 335 & 337 \\
\hline 430.8 & $\mathrm{~B}_{1 \mathrm{~g}}$ & 433 & & 409 & & \\
\hline 690.4 & $A_{g}$ & 708 & 700 & 705 & 700 & 702 \\
\hline 729.5 & $A_{g}$ & 728 & & 728 & & 725 \\
\hline 789.8 & $B_{1 \mathrm{~g}}$ & 796 & & & & \\
\hline 935.1 & $\mathrm{~B}_{1 \mathrm{~g}}$ & 942 & & & & \\
\hline 951.7 & $A_{g}$ & 956 & 952 & 958 & 952 & 959 \\
\hline 983.7 & $\mathrm{~A}_{\mathrm{g}}$ & 986 & & & & 987 \\
\hline 1057.6 & $A_{g}$ & 1064 & 1054 & 1059 & 1053 & 1060 \\
\hline 1143.6 & $\mathrm{~B}_{1 \mathrm{~g}}$ & 1150 & & & & \\
\hline 1192.6 & $\mathrm{~B}_{1 \mathrm{~g}}$ & 1204 & & & & \\
\hline \multirow[t]{2}{*}{1303.5} & $A_{g}$ & 1309 & & 1295 & 1289 & 1295 \\
\hline & & 1345 & & 1315 & 1330 & 1317 \\
\hline 1394.7 & $A_{g}$ & 1409 & & 1413 & & 1407 \\
\hline 1449.4 & $\mathrm{~A}_{\mathrm{g}}+\mathrm{B}_{1 \mathrm{~g}}$ & 1442 & 1456 & 1449 & & \\
\hline 1507.7 & $\mathrm{~A}_{\mathrm{g}}$ & 1505 & 1505 & 1510 & 1506 & 1507 \\
\hline 1549.4 & $A_{g}$ & 1540 & 1538 & 1544 & 1540 & 1540 \\
\hline 1570.4 & $A_{g}$ & 1559 & & & & 1553 \\
\hline
\end{tabular}

compare very well in terms of peak positions but less so in terms of line intensities. Differences in the intensities of the observed and predicted Raman for some of the bands, may be an indication of weak resonance effects in the recorded spectra. The predicted and measured vibrational frequencies for the Raman-active modes of $\mathrm{H}_{2}$ TAP are collected in Table IV and are found to be in good agreement. The DFT predicted vibrational frequencies are in approximate agreement with previously published results from Berezin et al. ${ }^{28}$ using the 6-31G $(d)$ basis set. Provided also in Table IV are the mode assignments obtained from the current DFT predictions. It is immediately evident that only the $\mathrm{A}_{\mathrm{g}}$ and $\mathrm{B}_{1 \mathrm{~g}}$ modes are actually observed. In agreement with the calculations, no outof-plane modes are present in the experimental spectra.

\section{Absorption spectra}

The absorption spectra of the two Q bands of $\mathrm{H}_{2}$ TAP in the three matrices used as hosts are presented in the left panel of Fig. 3. The spectra are clearly dominated by the intense $0-0$ band of the $Q_{x}$ transition near $600 \mathrm{~nm}$ with much weaker vibronic bands extending up to $550 \mathrm{~nm}$ but evidently not reaching the $\mathrm{Q}_{\mathrm{y}}$ band around $520 \mathrm{~nm}$. The $\mathrm{Q}_{\mathrm{x}}(0-0)$ bands are shown on an expanded wavelength scale in the panel on the right while the locations of the dominant feature of this transition are listed in Table I as 16653,16575 , and $16534 \mathrm{~cm}^{-1}$ in Ne, $\mathrm{N}_{2}$, and Ar, respectively. These values are all higher in energy than the positions of either of the tautomer doublets (16353 and $16300 \mathrm{~cm}^{-1}$ ) recorded ${ }^{22}$ for the $\mathrm{Q}_{\mathrm{x}}$ band in an n-octane
Shpol'skii matrix. To the best of our knowledge, this transition has never been recorded in the gas phase either under static cell conditions or in free jet expansions. However, from our previous matrix work ${ }^{6}$ on $\mathrm{H}_{2} \mathrm{Pc}$, where numerous gas phase

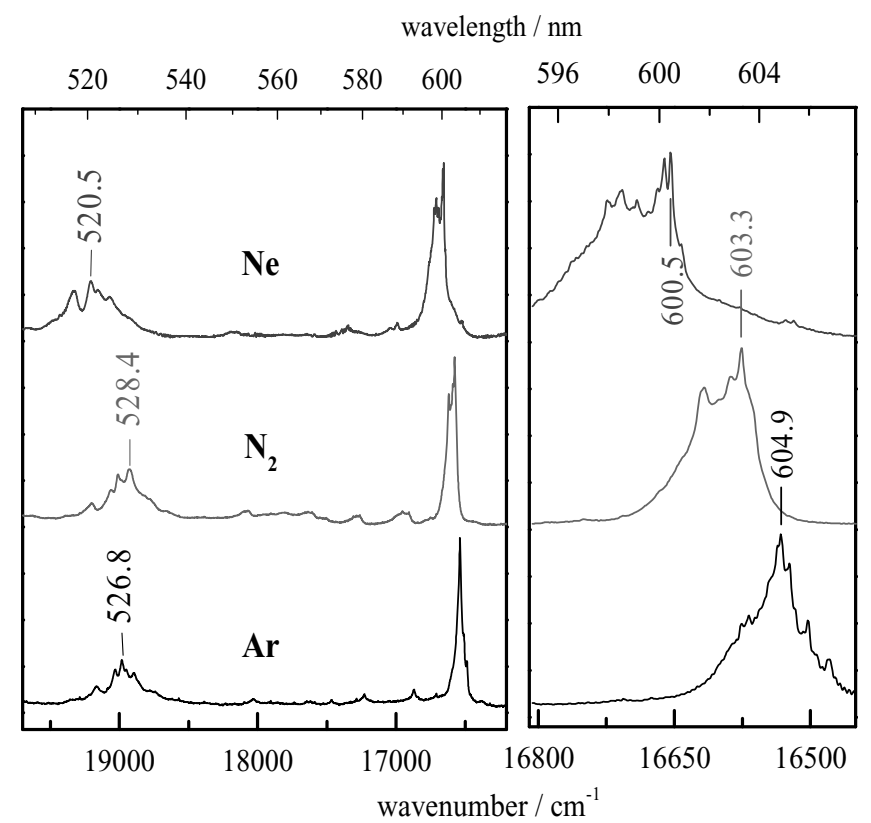

FIG. 3. A comparison of the visible absorption spectra recorded for $\mathrm{H}_{2}$ TAP in the low temperature hosts $\mathrm{Ne}, \mathrm{N}_{2}$, and Ar. The panel on the right hand side shows the structure present on the 0-0 band of the $Q_{x} \leftarrow G$ transition. Of particular note is the doublet splitting $\left(\Delta=6 \mathrm{~cm}^{-1}\right)$ evident on the $0-0$ band in neon. 
results ${ }^{15,16}$ also exist, we expect that the neon results will most closely match any future data for the free molecule. Accordingly, we identify the neon absorption values of $600.5 \mathrm{~nm}$ $\left(16653 \mathrm{~cm}^{-1}\right)$ and $520.5 \mathrm{~nm}\left(19211 \mathrm{~cm}^{-1}\right)$ listed in Table I as closest to the gas phase locations for the $Q_{x}$ and $Q_{y}$ band origins, respectively. The largest $\mathrm{Q}_{\mathrm{y}}-\mathrm{Q}_{\mathrm{x}}$ state splitting is also observed in neon $\left(2558 \mathrm{~cm}^{-1}\right)$ and a slightly larger value is anticipated in the gas phase.

The absorption bands recorded for the $Q_{y}$ state near $520 \mathrm{~nm}$ are broader than the $\mathrm{Q}_{\mathrm{x}}$ but do not appear to be overlapped significantly by any vibronic bands of the $Q_{x} \leftarrow G\left(S_{0}\right)$ transition. This is because the (average) matrix $Q_{y}-Q_{x}$ splitting of $\mathrm{H}_{2}$ TAP is of the order of $2400 \mathrm{~cm}^{-1}$ considerably larger than the frequency of all the fundamental molecular vibrations with the exception of the $\mathrm{C}-\mathrm{H}$ and $\mathrm{N}-\mathrm{H}$ stretches. This situation for $\mathrm{H}_{2}$ TAP is in stark contrast to its daughter molecule, $\mathrm{H}_{2} \mathrm{Pc}$, in which severe band overlap occurs at around $1000 \mathrm{~cm}^{-1}$, rendering the region of the band origin of the $\mathrm{Q}_{\mathrm{y}} \leftarrow \mathrm{G}$ transition congested, even in free jet conditions. ${ }^{16}$ As a result, the exact position of the band origin of the $\mathrm{Q}_{\mathrm{y}}$ state of $\mathrm{H}_{2} \mathrm{Pc}$ in the gas phase ${ }^{15,16}$ is still unknown. However, as will become clear in the excitation spectra, strong $Q_{y}$ $-Q_{x}$ state coupling also occurs for $\mathrm{H}_{2} \mathrm{TAP}$, which means the coupling vibronic bands of the $\mathrm{Q}_{\mathrm{x}}$ state must involve nonfundamental modes, i.e., combination or overtones.

As shown on the expanded plot in Fig. 3, the $Q_{x}$ absorption bands are highly structured in all three solids, with the band profile narrowest in argon and broadest in neon. Ar appears to be the simplest system with a single band dominating. In $\mathrm{Ne}$ the resolved features of the structured absorption band are narrow with the two strongest bands exhibiting a clear splitting of $\sim 6 \mathrm{~cm}^{-1}$. Evidence of site structure is present in all three matrices, but as will be shown ahead, site-selected excitation and hole-burning are more effective techniques to resolve the multitude of features overlapped in these complex absorption bands. The size of the $\mathrm{H}_{2}$ TAP molecule is very close to that of $\mathrm{H}_{2} \mathrm{P}$ for which site effects in rare gas matrices were investigated by means of visible spectroscopy by Radziszewski et al. ${ }^{31}$ The absorption band structure is partially due to the presence of $\mathrm{N}-\mathrm{H}$ tautomers which experience different matrix environments (see below, Sec. III F). The site structure for porphine was found especially complex in Ar and explained by the results of molecular dynamic calculations $^{32}$ showing that $\mathrm{H}_{2} \mathrm{P}$ occupies a large number of possible trapping sites. The same is expected for $\mathrm{H}_{2} \mathrm{TAP}$, consistent with the pronounced difference in the absorption bandshapes recorded by us in $\mathrm{Ne}$ and Ar matrices.

\section{Fluorescence}

The fluorescence spectra recorded for $\mathrm{H}_{2}$ TAP with $\mathrm{Q}_{x}$ state excitation are compared in Fig. 4 for the three matrices, revealing a series of bands extending out to $670 \mathrm{~nm}$. The presence of site structure is evident on all the bands in all matrices. Site effects could only be examined on the $Q_{x}$ band. Due to significant electron-phonon coupling strength, excitation into the band maximum excites the phonon-sidebands of all sites absorbing to the red of this. Thus the simplest emission, free

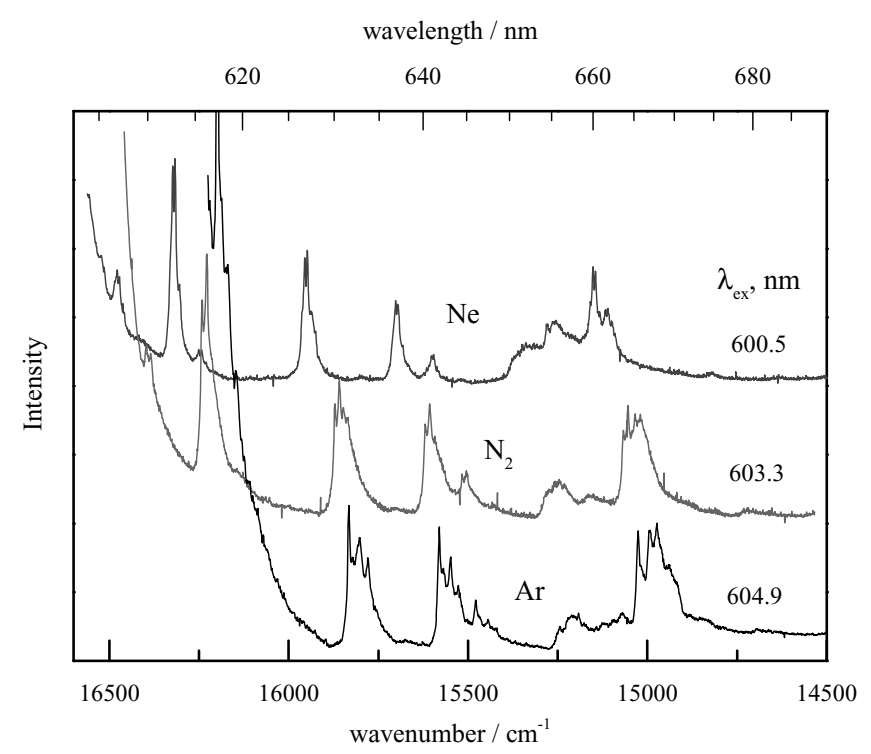

FIG. 4. Fluorescence recorded for $\mathrm{H}_{2}$ TAP isolated in $\mathrm{Ne}, \mathrm{Ar}$, and $\mathrm{N}_{2}$ matrices and produced with laser excitation at the indicated wavelengths.

of multiple site effects, is expected with excitation of structured features on the red wing of the absorptions. Additional details on the site structure are provided in the supplementary material $^{43}$ where Figure S1 summarizes site effects observed in the three matrices. The fluorescence recorded with $\mathrm{Q}_{\mathrm{y}}$ state excitation (data not shown) was even more complex due to the presence of multiple overlapping sites on each emission band. Neon showed the simplest behaviour revealing well resolved doublets even with $\mathrm{Q}_{\mathrm{y}}$ state excitation. This doublet structure matches that present in the absorption spectra shown in Fig. 3. The similarity of the fluorescence bands produced with $Q_{y}$ and $Q_{x}$ state excitations indicates complete $Q_{y} \rightarrow Q_{x}$ relaxation has occurred and only emission from the $Q_{x}$ state occurs as has been observed ${ }^{6}$ for $\mathrm{H}_{2} \mathrm{Pc}$ in matrices. The excited state lifetime in Ar was recorded as 4 ns-a value consistent with the fully allowed $\mathrm{Q}_{\mathrm{x}} \leftarrow \mathrm{G}$ absorption transition of $\mathrm{H}_{2}$ TAP.

In Fig. 5 a detailed comparison is made of the vibrational structure present in the fluorescence spectrum of $\mathrm{H}_{2}$ TAP isolated in a neon matrix and that present in the Raman spectra, both observed and predicted. The strong similarity between the spectra indicates that the Raman-active vibrational modes are the same as those observed in emission. Except for the band at $1320 \mathrm{~cm}^{-1}$ all the vibronic bands observed in fluorescence are thus transitions from $v^{\prime}=0$ to $v_{i}{ }^{\prime \prime}=1$ for fundamental vibrational modes i.e., no overtones or progressions are present. The agreement between the observed fluorescence and Raman modes has allowed us to make the vibronic mode assignments presented in Table IV. An inspection of the number and symmetries of the normal modes provided in Table IV indicates that the number of Raman modes is greatly reduced in the observed spectra. Moreover, from the bands presented in Table IV it is evident that only the $\mathrm{A}_{\mathrm{g}}$ modes carry significant intensity in the recorded spectra.

An aspect made obvious in the detailed comparison of the neon emission and the Raman spectra shown in Fig. 5 is the intensity disagreement present in the 700 and $1000 \mathrm{~cm}^{-1}$ 

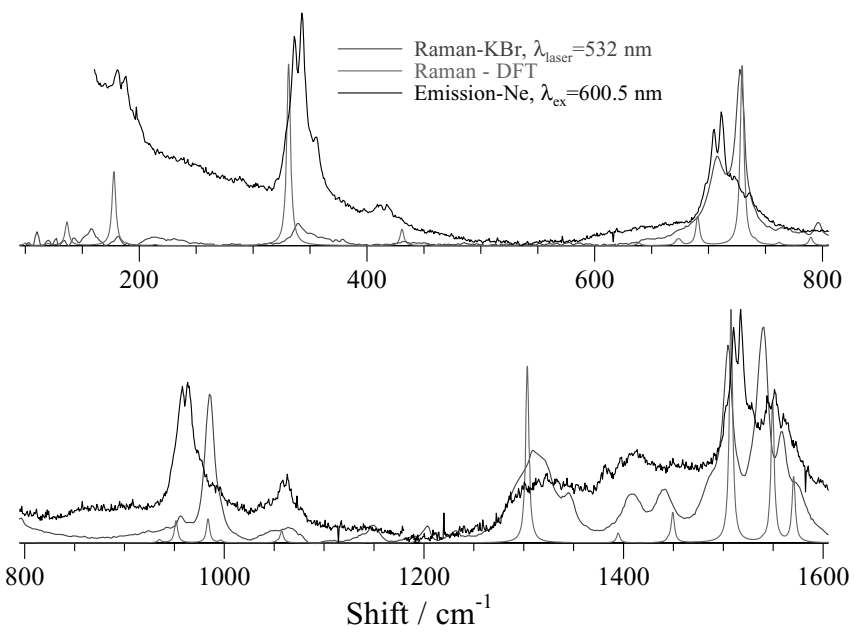

FIG. 5. A comparison of the fluorescence spectrum of $\mathrm{H}_{2}$ TAP in $\mathrm{Ne}\left(\lambda_{\text {ex }}\right.$ $=600.5 \mathrm{~nm})$ with the recorded Raman scattering $\left(\lambda_{\text {laser }}=532 \mathrm{~nm}\right)$ and the DFT predicted Raman spectra. The emission spectrum is shown linear in energy as a shift from the position of the $Q_{X}(0-0)$ state band origin. The doublet splitting present on the $\mathrm{Q}_{\mathrm{x}}(0-0)$ state absorption band (Fig. 3) is clearly evident on all the emission bands. The presence of unstructured bands in the $1400 \mathrm{~cm}^{-1}$ region $(650 \mathrm{~nm})$ may be an indication of some impurities in the sample.

regions. Examination of the atomic motions provided by DFT calculations for the intense Raman vibrational modes in these regions reveals that both involve motions of the pyrrole ring. The one at $700 \mathrm{~cm}^{-1}$ is a rocking mode in the pyrrole while the higher energy mode involves $\mathrm{C}-\mathrm{C}$ stretching in the pyrrole ring.

\section{E. Excitation}

Excitation spectra were recorded for $\mathrm{H}_{2}$ TAP isolated in $\mathrm{Ne}, \mathrm{Ar}$, and $\mathrm{N}_{2}$ by monitoring site-specific emission and scanning with the dye laser. As made evident in the comparison shown in Fig. 6 where the absorption and excitation data of

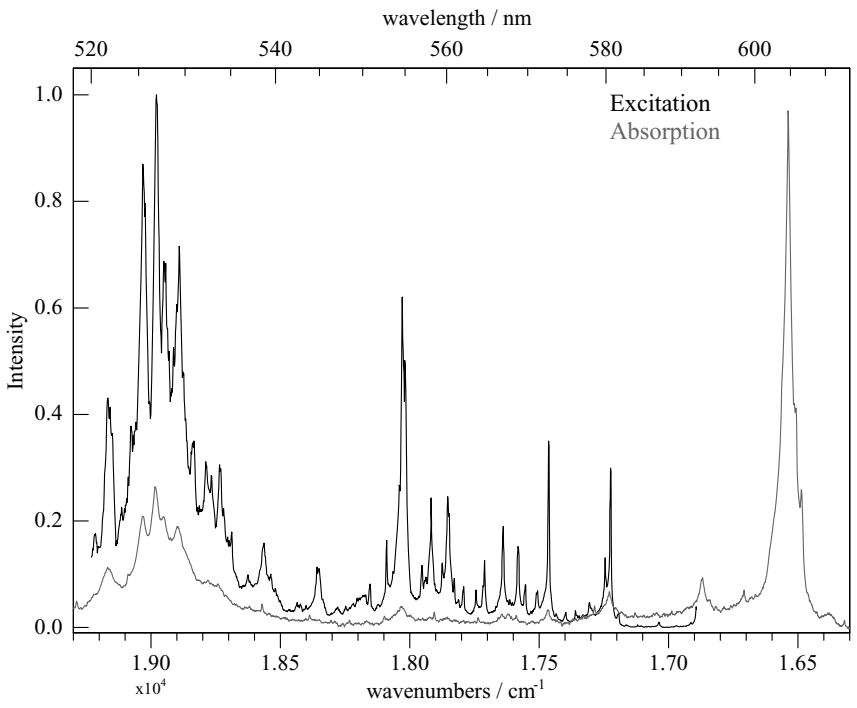

FIG. 6. A comparison of the $\mathrm{H}_{2}$ TAP absorption and laser excitation $\left(\lambda_{\mathrm{em}}\right.$ $=604.9 \mathrm{~nm}$ ) spectra recorded for $\mathrm{H}_{2}$ TAP in Ar matrices at $8 \mathrm{~K}$.

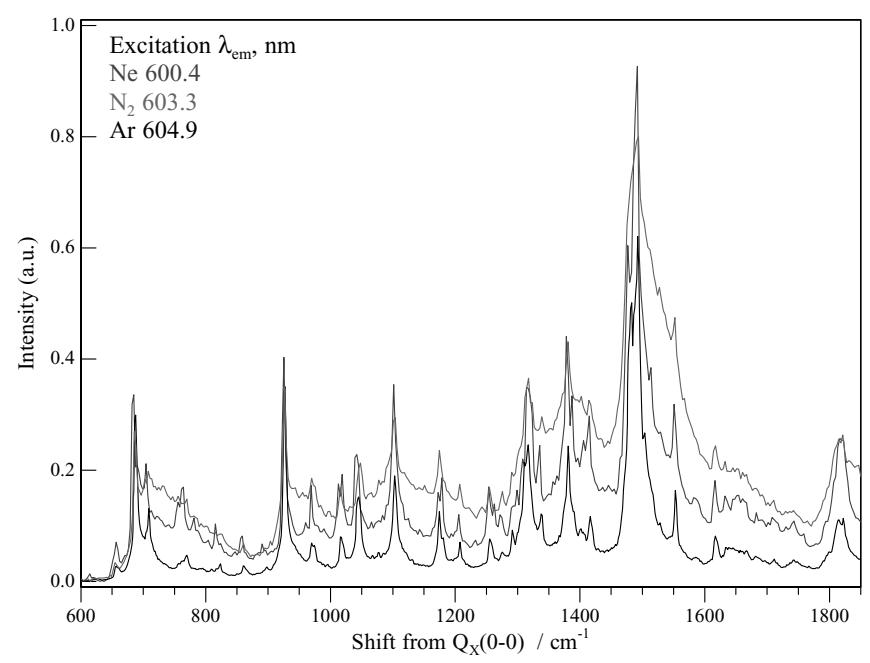

FIG. 7. Site-selected excitation spectra recorded for $\mathrm{H}_{2}$ TAP isolated in Ar, $\mathrm{Ne}$, and $\mathrm{N}_{2}$ matrices. In all three cases very similar band shapes and locations are observed. The values extracted in these scans are collected in Table V.

$\mathrm{H}_{2}$ TAP/Ar are both presented, a vast improvement is achieved in the identification of vibronic bands in the excitation scans. This enhancement is a direct result of the site-selective nature of the emission bands monitored. The shifts of these excitation bands from their origins are shown together in Figs. 7 and 8 for the three matrix systems. Excellent agreement clearly exists in the three systems up to around $2100 \mathrm{~cm}^{-1}$. The highest frequency band that coincides in all systems is at 2089 $\mathrm{cm}^{-1}$ as shown in Fig. 8. Moreover, the positions of these bands agree very well with those obtained in previous work ${ }^{19}$ done on $\mathrm{H}_{2}$ TAP isolated in Shpol'skii matrices.

The vibronic structure on the $\mathrm{Q}_{\mathrm{x}} \leftarrow \mathrm{G}$ transition is well resolved in excitation spectra and the extracted vibrational frequencies are collected in Table $\mathrm{V}$ up to $1650 \mathrm{~cm}^{-1}$. The most resolved excitation bands were obtained in Ar, especially when recorded by monitoring the (0-0) band-the maximum intensity of the $Q_{x}$ state emission. For example, it was

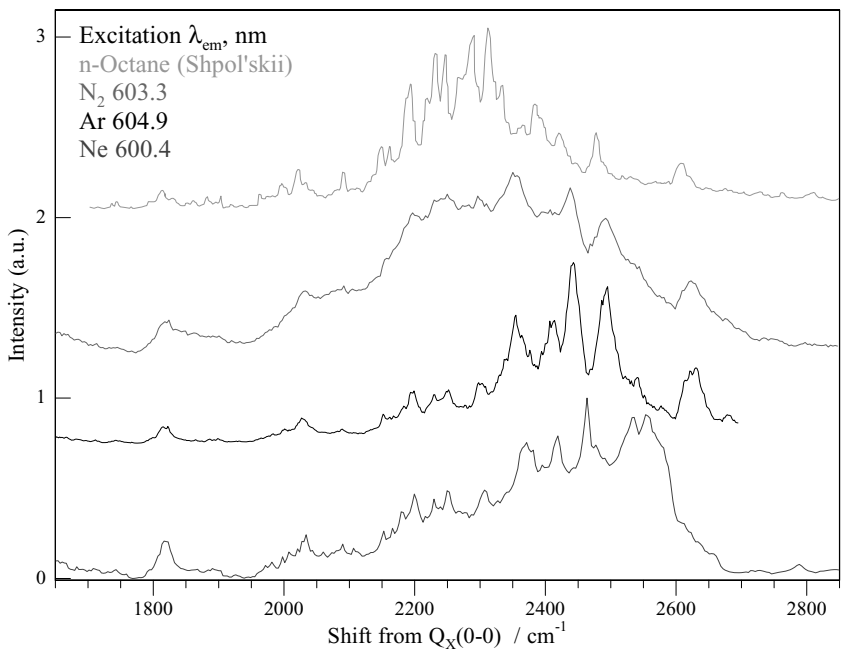

FIG. 8. The excitation spectra recorded for $\mathrm{H}_{2}$ TAP isolated in $\mathrm{Ar}, \mathrm{Ne}, \mathrm{N}_{2}$, and Shpol'skii matrices [Ref. 19] in the region of the $\mathrm{Q}_{\mathrm{y}}(0-0)$ band absorption. 
TABLE V. Vibrational frequencies $\left(\mathrm{cm}^{-1}\right)$ of the excited $\mathrm{Q}_{\mathrm{x}}$ state of $\mathrm{H}_{2}$ TAP extracted from the recorded excitation spectra of the molecule isolated in $\mathrm{N}_{2}$, $\mathrm{Ne}, \mathrm{Ar}$, and Shpol'skii [Ref. 19] matrices. These values are compared with the recorded vibronic frequencies extracted from the neon emission spectra. The symmetry assignments given in parentheses are from the DFT results obtained for the Raman-active modes. Values corresponding to the most intense bands observed in our study are shown in bold font while (b) indicates a broad band.

\begin{tabular}{|c|c|c|c|c|c|}
\hline \multicolumn{2}{|c|}{ Emission } & \multicolumn{4}{|c|}{ Excitation } \\
\hline & $\mathrm{Ne}$ & $\mathrm{Ne}$ & $\mathrm{N}_{2}$ & $\mathrm{Ar}$ & Shpol'skii \\
\hline & $\left(B_{1 g}\right)$ & & & 137 & \\
\hline 181 & $\left(A_{g}\right)$ & 171 & 177 & 175 & 179 \\
\hline \multirow[t]{3}{*}{336} & $\left(A_{g}\right)$ & 334 & 326 & 327 & 332 \\
\hline & & & & 502 & \\
\hline & & 656 & 657 & 655 & 665 \\
\hline 705 & $\left(A_{g}\right)$ & 685 & 688 & 688 & 689 \\
\hline \multirow[t]{5}{*}{728} & $\left(A_{g}\right)$ & 705 & 710 & 709 & 711 \\
\hline & & 764 & 758 & 770 & 760 \\
\hline & & 816 & 826 & 824 & 819 \\
\hline & & 859 & & 860 & 869 \\
\hline & & 891 & & 898 & 891 \\
\hline \multirow[t]{3}{*}{958} & $\left(A_{g}\right)$ & 925 & 929 & 927 & 933 \\
\hline & & 969 & 972 & 970 & 972 \\
\hline & & 1019 & 1019 & 1016 & 1024 \\
\hline \multirow[t]{6}{*}{1059} & $\left(A_{g}\right)$ & 1042 & 1051 & 1045 & 1044 \\
\hline & & 1101 & 1106 & 1103 & 1103 \\
\hline & & 1173 & 1177 & 1175 & 1171 \\
\hline & & 1206 & 1210 & 1208 & 1221 \\
\hline & & 1254 & 1257 & 1255 & 1263 \\
\hline & & 1272 & 1278 & 1276 & 1271 \\
\hline 1295 & $\left(A_{g}\right)$ & 1314 (b) & $1320(b)$ & 1311 & 1308 \\
\hline \multirow[t]{2}{*}{1315} & & & & 1317 & 1315 \\
\hline & & 1335 & 1339 & 1338 & 1336 \\
\hline 1413 & $\left(A_{g}\right)$ & 1378 & 1384 & 1381 & 1382 \\
\hline 1449 & $\left(A_{g}+B_{1 g}\right)$ & 1415 & 1417 & 1416 & 1418 \\
\hline 1510 & $\left(A_{g}\right)$ & 1477 & & 1483 & 1480 \\
\hline \multirow[t]{4}{*}{1544} & $\left(A_{g}\right)$ & 1492 & 1496 (b) & 1493 & 1496 \\
\hline & & & & 1504 & 1506 \\
\hline & & 1551 & 1555 & 1553 & 1556 \\
\hline & & 1620 & 1617 & 1617 & 1620 \\
\hline
\end{tabular}

possible in this case to distinguish the two bands with vibrational energies around $1315 \mathrm{~cm}^{-1}$. In contrast, bands are quite broad in $\mathrm{N}_{2}$, leading in particular to a single intense band with a vibrational energy at $1496 \mathrm{~cm}^{-1}$, instead of two. In situations where only a small change in geometry occurs between the excited and the ground state, a mirror image of the emission vibronic distribution is expected in the excitation. This has been observed by us ${ }^{6}$ previously for matrixisolated $\mathrm{H}_{2} \mathrm{Pc}$. Following this expectation, a tentative correspondence between emission and excitation values is given in Table V. However, as is evident there, excitation spectra reveal the presence of many more bands than the fundamental modes present in emission. Vibrational modes of $\mathrm{B}_{1 \mathrm{~g}}$ symmetry can appear in excitation spectra because of the coupling between $\mathrm{Q}_{\mathrm{x}}$ and $\mathrm{Q}_{\mathrm{y}}$ excited states. Moreover, the additional vibrational structure in excitation can arise from overtones or combination bands. No specific assignments are made in the present study.
It is also evident in Table $\mathrm{V}$ that the vibrational frequencies in excitation are systematically lower than their equivalent mode in emission. Such behaviour was already observed in the absorption ${ }^{31}$ and emission data ${ }^{33}$ for $\mathrm{H}_{2} \mathrm{P}$. From this observation it can be inferred that the force constants in the $Q_{x}$ state are lower than in the ground state. It is a consequence of the reduced electronic density in the occupied orbitals in the excited state which implies small changes in the internuclear distances in the ground and excited states of $\mathrm{H}_{2}$ TAP. Both systems are in contrast to $\mathrm{H}_{2} \mathrm{Pc}$ in which little or no changes in the ground and excited state vibrational modes were detected. ${ }^{6,15}$ This difference signals the stabilising influence of the four benzo groups on the central tetra-pyrrole ring in $\mathrm{H}_{2} \mathrm{Pc}$ - an effect which is absent in the parent molecules $\mathrm{H}_{2}$ TAP and $\mathrm{H}_{2} \mathrm{P}$.

In contrast to the lower energy region, the excitation band positions above $2100 \mathrm{~cm}^{-1}$ differ from host to host with, as shown in Fig. 8, the most pronounced differences occurring in the $2200-2700 \mathrm{~cm}^{-1}$ range. Considerable differences also exist in the band shapes for the four hosts in this spectral region. This is the location of the band origin of the $Q_{y}$ state which is known from the absorption spectra to shift from host to host, see Fig. 3 and Table I for specific values. We have also observed that the $Q_{y}-Q_{x}$ state splittings are different for the blue and red sites in a given host with the red site exhibiting the larger values. Shifts of around $20 \mathrm{~cm}^{-1}$ in the $\mathrm{Q}_{\mathrm{x}}(0-0) \mathrm{ab}-$ sorption band correspond to a difference of around $100 \mathrm{~cm}^{-1}$ in the $Q_{y}-Q_{x}$ state splittings. This pattern is consistent with what has been previously observed ${ }^{19,20,22}$ in Shpol'skii matrices. These site effects exhibit the same tendency as the host effects presented in Table I, viz., the lower the energy of the $Q_{x}(0-0)$ band the smaller the splitting between the $Q_{y}-Q_{x}$ state. This behaviour indicates that the influence of the host material is greater for the $Q_{y}$ than the $Q_{x}$ state.

\section{F. Hole-burning}

The purpose of this investigation was to study the ability of $\mathrm{H}_{2}$ TAP molecules isolated in the rare gas and nitrogen matrices to exhibit $\mathrm{PSHB}^{34}$ and to establish the spectral position of their photo-transformation products. It is known that photo-induced NH-tautomerism, i.e., the migration of the two inner hydrogen atoms to the opposite pair of nitrogen atoms (see Fig. 1) at the centre of the tetrapyrrole macrocycle is an observable phenomenon at low temperatures in the $\mathrm{H}_{2} \mathrm{Pcs}^{35}$ and $\mathrm{H}_{2} \mathrm{Ps} .{ }^{31,35-37}$ This effect provides a "photochemical" PSHB mechanism for these molecules. ${ }^{38,39}$ Furthermore, for the symmetrical porphyrins and phthalocyanines the absorption band of the photoproduct is located within the envelope of the initial absorption band. NH-tautomerism dominates the "non-photochemical or photophysical" PSHB mechanism which is based on the standard model of two-level systems in amorphous media ${ }^{40}$ (model "Two Level System", TLS). Like site-selected emission, hole-burning spectroscopy can also be used to reveal sites that are not evident in the absorption spectra.

The present experiments have shown (see Fig. 3) that at low temperatures, the $\mathrm{Q}_{\mathrm{x}}(0-0)$ absorption band of $\mathrm{H}_{2} \mathrm{TAP}$ 

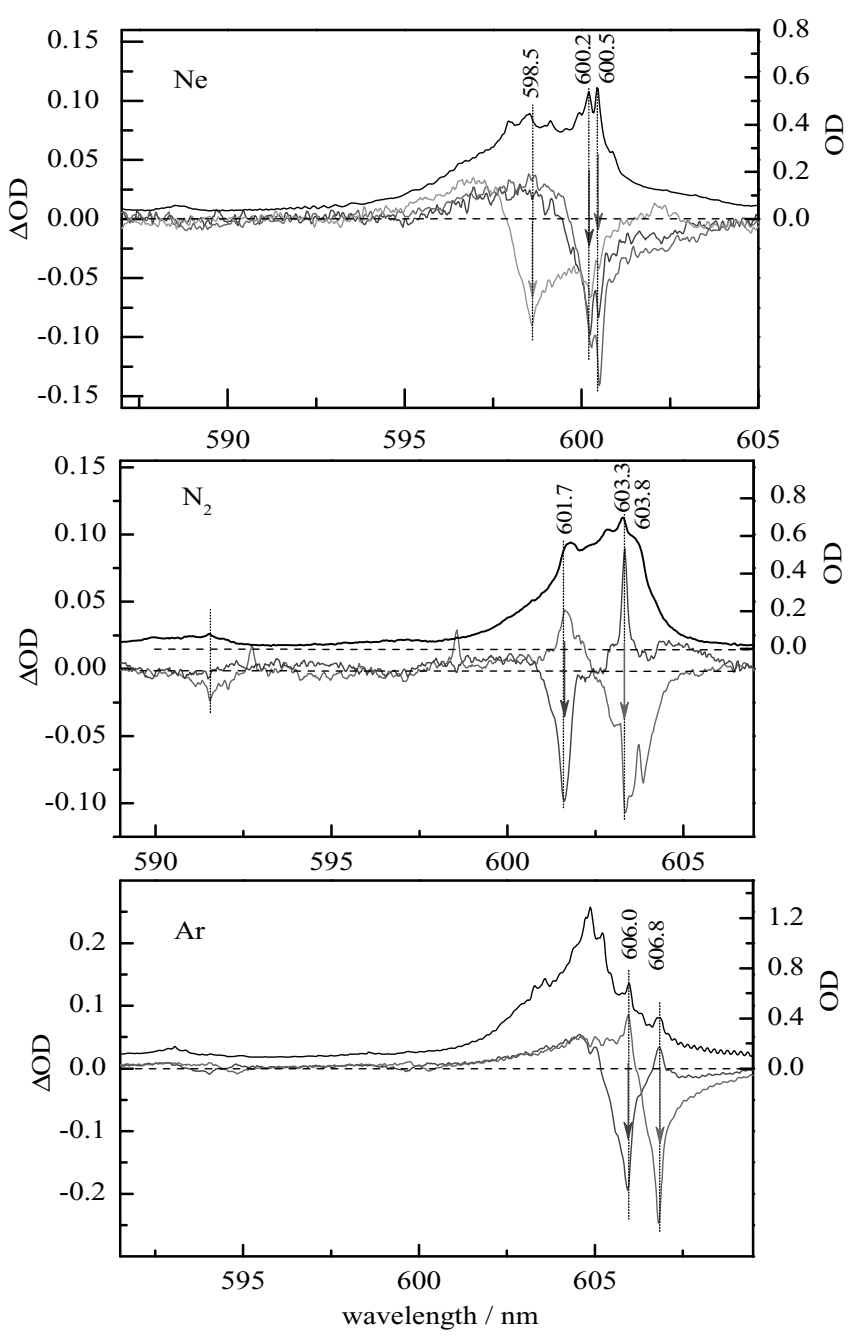

FIG. 9. The hole-burning characteristics observed for $\mathrm{H}_{2}$ TAP in solid $\mathrm{Ne}$ (top), $\mathrm{N}_{2}$ (middle) and Ar (bottom) matrices. Colour curves are subtractions spectra between absorptions just before and just after laser excitation of the sample; the laser wavelengths used to burn holes are mentioned together with arrows of the same colour as the curves. For each matrix host, the results reported in the figure were obtained in the same sample, a white lamp being used between each laser excitation in order to come back to the original absorption profile. For comparison these original absorption spectra recorded for the $\mathrm{Q}_{\mathrm{x}}(0-0)$ band in the three matrices are also shown. Holes and antiholes are clearly observed in $\mathrm{Ar}$ and $\mathrm{N}_{2}$ (blue and red curves), corresponding to spectral lines of tautomers. See text for details.

in all matrices is inhomogeneously broadened-the necessary condition for the formation of holes. Fig. 9 shows the $\mathrm{Q}_{\mathrm{x}}(0-0)$ region of the $\mathrm{H}_{2} \mathrm{TAP}$ absorption for the identification of molecular sites in the three matrices with PSHB. It is evident in the data shown that the resonant laser irradiation transforms large amounts of $\mathrm{H}_{2}$ TAP sites and generates considerable changes in profile of the inhomogeneous absorption band. The high efficiency of hole creation confirms burning based on the NH-tautomerism of $\mathrm{H}_{2}$ TAP. The tautomerism observed in the three matrices is characterised by various spectral changes of the parent and the photoproduct, which are matrix dependent because of the introduction of $\mathrm{H}_{2}$ TAP molecules into specific sites of each of the three crystalline matrices.

Numerous experiments conducted by us have shown complex correlations between the spectral sites of $\mathrm{H}_{2}$ TAP, observed through phototransformation in all of the matrices used. However, the lack of clear mutual phototransformation is a consequence of (i) the large number of sites of isolation of $\mathrm{H}_{2}$ TAP in $\mathrm{N}_{2}$, Ar, and Ne matrices and of (ii) the resulting overlap of the strongest spectral lines at different sites in the region of the $\mathrm{Q}_{\mathrm{x}}(0-0)$ absorption band. The second point does not allow for excitation of a single, distinct site using one specific laser wavelength. Note that in the case of low-dose irradiation and the presence in the system of large numbers of sites and considerable electron-phonon coupling, the profile of the hole is perfectly symmetrical and consists of the zero phonon hole (ZPH) accompanied by two phonon side-bands. One is the "true" phonon band-on the high frequency side, while the other (on the low frequency side) is the "pseudo" band of phonons, ${ }^{41}$ which reveals the strength of the electron-phonon coupling experienced by the guest molecule in the host solid. From this overlap we can interpret the different holes formed in the first instance, by the possibility of simultaneous burning of some sites in which the spectral position of the $\mathrm{ZPH}$ is very close. Further analysis of the shape of the hole arising from NH-tautomerism must take into account the absorption profile of the photoproduct. This is so, because if the photoproduct absorption overlaps the "true" or "pseudo" phonon band of the hole, the resulting PSHB profile will be altered, with parts being even either positive or negative, depending on the weight of each contribution with their opposite signs. Due to this complexity, arising from the superposition of the hole and the anti-hole frequencies, far-reaching interpretation of the observed spectral changes requires additional studies. Nonetheless, as indicated in Fig. 9, we have been able to identify centers that are linked by the process of phototransformation with molecules occupying sites corresponding to the most intense line in the band region $\mathrm{Q}_{\mathrm{x}}(0-0)$ absorption.

We began the PSHB investigations by choosing the laser frequencies to match the most intense components of the $\mathrm{Q}_{\mathrm{X}}(0-0)$ absorption bands. The result in nitrogen is reported in Fig. 9, middle panel, red curve with a laser wavelength at $603.3 \mathrm{~nm}$. One can see that the site of the photoproduct (anti-hole) appears at higher energy $(601.7 \mathrm{~nm})$. Once the spectral location of the anti-hole was identified, irradiation at this wavelength was used to demonstrate that the hole-burning process was reversible. This behaviour is depicted in Fig. 9, middle panel, blue curve with a spectral hole at $601.7 \mathrm{~nm}$ and the anti-hole at $603.3 \mathrm{~nm}$. The spectral shift between these centers is $\Delta v \approx 44 \mathrm{~cm}^{-1}$. In Ne matrices, the main doublet at $600.2 \mathrm{~nm}$ and $600.5 \mathrm{~nm}$ was assumed to belong to main sites occupied by the two tautomers. However, it was impossible to confirm this with the PSHB results because of the very small shift $\left(\Delta v \approx 6 \mathrm{~cm}^{-1}\right)$ between the ZPH bands and the large electron-phonon coupling, as previously explained. The two spectral holes are depicted in Fig. 9, upper panel, by the red and blue curves. Both excitations lead to a depopulation of the two sites, with the anti-hole at frequencies of minor sites. This behaviour is interpreted as a consequence of slight rearrangements of $\mathrm{Ne}$ atoms in the immediate vicinity of $\mathrm{H}_{2}$ TAP, in this matrix which is especially soft at $8 \mathrm{~K}$. Burning a hole in the high frequency range of the absorption band in $\mathrm{Ne}$ did not reveal evident anti-holes, as indicated in the green curve, Fig. 9, upper panel. On the contrary, holes at the frequencies 
of the main sites clearly appear even in this case, meaning that phototransformations occur efficiently in these major sites via phonon excitation.

In Ar, the hole obtained by laser excitation in the maximum of absorption at $604.9 \mathrm{~nm}$ was not found to be clearly correlated with an anti-hole. We suspect that the photoinduced tautomers absorb at very close frequencies, and that, as in the case of $\mathrm{Ne}$, it was not possible to identify clear frequencyselected sites to both tautomers from the PSHB results. On the other hand, correlated holes and anti-holes have been clearly identified with excitations in the red part of the absorption profile, as shown Fig. 9, bottom panel, red and blue curves. Accordingly, the shift between the $606.0 \mathrm{~nm}$ and $606.8 \mathrm{~nm}$ site pairs of $\mathrm{H}_{2}$ TAP/Ar linked by phototransformation $(\Delta v$ $\approx 22 \mathrm{~cm}^{-1}$ ) is large enough to avoid the contamination due to phonon and pseudo-phonon side band excitations. In the absorption profile of the excited vibrational $\mathrm{Q}_{\mathrm{x}}(0-1)$ band (between $588 \mathrm{~nm}$ and $593 \mathrm{~nm}$ ) it is noteworthy that spectral holes and anti-holes appear (Fig. 9, bottom panel) with selective excitation to the $\mathrm{Q}_{\mathrm{x}}(0-0)$ band, an effect which is entirely expected.

The PSHB observed for $\mathrm{H}_{2}$ TAP was found to be different in the three hosts studied. This behaviour matches very well the previous PSHB observations made by Michl and coworkers $^{31}$ for $\mathrm{H}_{2} \mathrm{P}$ in different rare gas hosts. Even though both molecules are predicted to be planar (with $\mathrm{D}_{2 \mathrm{~h}}$ symmetry), $\mathrm{H}_{2}$ TAP is smaller in size due to the absence of $\mathrm{H}$ atoms attached at the bridging $\mathrm{N}$ atoms leading to a possible difference in the sites occupied, especially in neon as has been observed. However, in the case of $\mathrm{H}_{2} \mathrm{P}$ in neon spectra were recorded at temperatures $(4 \mathrm{~K})$ significantly lower than the value of $8 \mathrm{~K}$ used in the present study. Xenon matrices were found to show a simpler case for $\mathrm{H}_{2} \mathrm{P}$, but this host was not explored in the present work.

\section{CONCLUSIONS}

We have investigated the electronic spectra of $\mathrm{H}_{2}$ TAP isolated in rare gas and nitrogen matrices. A comparison of the room temperature $\mathrm{KBr}$ Raman and fluorescence spectra reveals strong similarities and when compared with DFT predicted Raman spectra, assignments of the vibronic modes have been possible. The close agreement is consistent with the similarities in the selection rules for both types of transitions. In contrast, excitation spectra are much richer showing many resolved vibronic bands when site-selected features are monitored. Excitation scans done in the region of the $\mathrm{Q}_{\mathrm{y}}$ band are complex and shift significantly from host to host.

The observed fundamental vibronic frequencies in the ground $(\mathrm{G})$ and the lowest frequency modes of the first excited $\left(\mathrm{Q}_{\mathrm{x}}\right)$ state of $\mathrm{H}_{2}$ TAP are similar but particularly beyond around $500 \mathrm{~cm}^{-1}$ the frequencies differ with values of the dominant bands consistently lower in excitation than emission. This indicates changes in the binding potentials in the ground and excited states of $\mathrm{H}_{2}$ TAP and matches earlier findings for $\mathrm{H}_{2} \mathrm{P}$. Such changes were not observed in $\mathrm{H}_{2} \mathrm{Pc}$, possibly because of the stabilising influence of the presence of the four benzo groups on the central tetrapyrrole ring. Moreover, the resolved vibronic features above $500 \mathrm{~cm}^{-1}$ in the excita- tion spectra are much more numerous than in emission. This is likely due to the occurrence of combination and overtone bands in the excited $Q_{x}$ state. The existence of the second exited $Q_{y}$ state more than $2200 \mathrm{~cm}^{-1}$ above $Q_{x}$ is responsible for the observation of complex excitation spectra due to nonadiabatic coupling between electronic and vibrational states.

Hole-burning spectroscopy was also used to investigate the site occupancy of $\mathrm{H}_{2}$ TAP isolated as the guest molecule in the $\mathrm{Ne}, \mathrm{Ar}$, and $\mathrm{N}_{2}$ host solids. The complicated site structure of $\mathrm{H}_{2}$ TAP is still not fully understood. Further studies, in particular molecular dynamics calculations would be instructive to examine the site geometries especially in comparison with matrix-isolated $\mathrm{H}_{2} \mathrm{P}$. A comparative vibrational analysis of $\mathrm{H}_{2}$ TAP and MgTAP based on matrix-IR data is currently underway and will be the subject of a future publication. Moreover, the results of stimulated emission observed for $\mathrm{H}_{2}$ TAP are currently being analysed in a close comparison with our previous findings ${ }^{25,26,42}$ in a variety of matrixisolated tetrapyrrole molecules. ${ }^{43}$

\section{ACKNOWLEDGMENTS}

This work was supported by the BRFFR-CNRS exchange grants (Grant Nos. F09F-001/23181 and F11F-001/24 692) and the CNRS projects. The assistance of the Ulysses FranceIreland research exchange grant (Grant No. 2011) is also acknowledged. Chris Henchy is grateful for the award of an NUIM Hume scholarship and to Dr. Ann Shanahan at the Fócas Research Institute, DIT Dublin for recording the Raman spectra.

${ }^{1}$ F. M. Moser and A. L. Thomas, Phthalocyanine Compounds (Reinhold Publishing Corporation, New York, 1969).

${ }^{2}$ T. Hanada, H. Takiguchi, Y. Okada, Y. Yoshida, N. Tanigaki, and K. Yase, J. Cryst. Growth 204(3), 307-310 (1999).

${ }^{3}$ J. L. Bredas, C. Adant, P. Tackx, and A. Persoons, Chem. Rev. 94(1), 243278 (1994).

${ }^{4}$ C. M. Allen, W. M. Sharman, and J. E. Van Lier, J. Porphyrins Phthalocyanins 5, 161 (2001).

${ }^{5}$ R. P. Linstead and M. Whalley, J. Chem. Soc. 4839 (1952).

${ }^{6}$ C. Murray, N. Dozova, J. G. McCaffrey, N. Shafizadeh, W. Chin, M. Broquier, and C. Crépin, Phys. Chem. Chem. Phys. 13, 17543 (2011).

${ }^{7}$ P. Geissinger, L. Kaldor, and D. Haarer, Phys. Rev. B. 53, 4356 (1996).

${ }^{8}$ B. J. Prince, B. E. Williamson, and R. J. Reeves, J. Lumin. 93, 293-301 (2001).

${ }^{9}$ L. Bajema, M. Gouterman, and B. Meyer, J. Mol. Spectrosc. 27, 225 (1968).

${ }^{10}$ V. E. Bondybey and J. H. English, J. Am. Chem. Soc. 101, 3446 (1979).

${ }^{11}$ A. Stendal, U. Beckers, S. Wilbrandt, O. Stenzel, and C. von Borczyskowski, J. Phys. B 29, 2589-2595 (1996).

${ }^{12}$ D. Eastwood, L. Edwards, M. Gouterman, and J. Steinfeld, J. Mol. Spectrosc. 20(4), 381-390 (1966).

${ }^{13}$ L. Edwards and M. Gouterman, J. Mol. Spectrosc. 33, 292 (1970).

${ }^{14}$ A. Slenczka, B. Dick, M. Hartmann, and J. P. Toennies, J. Chem. Phys. 115, 10199 (2001).

${ }^{15}$ F. L. Plows and A. C. Jones;, J. Mol. Spectrosc. 194(2), 163-170 (1999).

${ }^{16}$ P. S. H. Fitch, L. Wharton, and D. H. Levy, J. Chem. Phys. 73, 1064 (1980); P. S. H. Fitch, Ch. A. Hayman, and D. H. Levy, ibid. 74, 6612 (1981).

${ }^{17}$ M. Hartmann, A. Lindinger, J. P. Toennies, and A. F. Vilesov, Phys. Chem. Chem. Phys. 4, 4839 (2002); R. Lehnig, J. Sebree, and A. Slenczka, J. Phys. Chem. A 111, 7576 (2007).

${ }^{18}$ R. Lehnig and A. Slenczka, J. Chem. Phys. 118, 8256 (2003); 120, 5064 (2004); R. Lehnig, M. Slipchenko, S. Kuma, T. Momose, B. Sartakov, and A. F. Vilesov, ibid. 121, 9396 (2004). 
${ }^{19}$ W.-Y. Huang, S. Salmon, G. Jean-Charles, E. van Riper, and L. W. Johnson, Spectrochim. Acta A 52, 157 (1996).

${ }^{20}$ S. M. Arabei, K. N. Solov'ev, and E. A. Makarova, J. Appl. Spectrosc. 71, 35 (2004).

${ }^{21}$ L. L. Gladkov, S. F. Shkirman, V. K. Konstantinova, and K. N. Solov'ev, J. Appl. Spectrosc. 67, 755 (2000).

${ }^{22}$ S. M. Arabei, V. A. Kuzmitsky, and K. N. Solovyov, Opt. Spectrosc. 102, 692 (2007).

${ }^{23}$ E. A. Makarova, G. V. Koroleva, O. L. Tok, and E. A. Luk'yanets, J. Porphyrins Phthalocyanines 4, 525 (2000).

${ }^{24}$ C. Gée, A. Cuisset, L. Divay, and C. Crépin, J. Chem. Phys. 116, 4993 (2002).

${ }^{25}$ N. Dozova, C. Murray, J. G. McCaffrey, N. Shafizadeh, and C. Crépin, Phys. Chem. Chem. Phys. 10, 2167 (2008).

${ }^{26}$ C. Crépin, N. Shafizadeh, W. Chin, J.-P. Galaup, J. G. McCaffrey, and S. M. Arabei, Low Temp. Phys. 36, 451 (2010).

${ }^{27}$ C. Murray, N. Dozova, J. G. McCaffrey, S. FitzGerald, N. Shafizadeh, and C. Crépin, Phys. Chem. Chem. Phys. 12, 10406 (2010).

${ }^{28}$ K. V. Berezin and V. V. Nechaev, J. Appl. Spectrosc. 70, 344 (2003).

${ }^{29}$ M. J. Frisch, G. W. Trucks, H. B. Schlegel et al., Gaussian 03, Revision E.01, Gaussian, Inc., Wallingford, CT, 2004.

${ }^{30}$ C. Henchy, C. Murray, C. Crépin, and J. G. McCaffrey, Can. J. Chem. 90, 1078 (2012).
${ }^{31}$ J. G. Radziszewski, J. Waluk, and J. Michl, J. Mol. Spectrosc. 140, 373 (1990).

${ }^{32}$ A. Kyrychenko and J. Waluk, J. Chem. Phys. 119, 7318 (2003).

${ }^{33}$ J. R. Radziszewski, J. Waluk, M. Nepras, and J. Michl, J. Phys. Chem. 95, 1963 (1991).

${ }^{34}$ R. Jankowiak, J. M. Hayes, and G. J. Small, Chem. Rev. 93, 1471 (1993).

${ }^{35}$ I. E. Zalesskii, V. N. Kotlo, A. N. Sevchenko, K. N. Solov'ev, and S. F. Shkirman, Sov. Phys. Dokl. 17, 1183 (1973).

${ }^{36}$ S. Völker and R. M. Macfarlane, Mol. Cryst. Liq. Cryst. 50, 213 (1979).

${ }^{37}$ S. F. Shkirman, S. M. Arabei, and G. D. Egorova, J. Appl. Spectrosc. 31, 1370 (1979).

${ }^{38}$ A. A. Gorokhovskii, R. K. Kaarli, and L. A. Rebane, J. Exp. Theor. Phys. Lett. 20, 216 (1974).

${ }^{39}$ S. Völker and J. H. van derWaals, Mol. Phys. 32, 1703 (1976).

${ }^{40}$ J. M. Hayes and G. J. Small, Chem. Phys. 27, 151 (1978).

${ }^{41}$ J.-P. Galaup, in Advances in Multi-Photon Processes and Spectroscopy, edited by S. H. Lin, A. A. Villaeys, and Y. Fujimura (World Scientific, 2004), Vol. 16, p. 73

${ }^{42}$ S. M. Arabei, C. Crépin, N. Shafizadeh, J. G. McCaffrey, and J.-P. Galaup, Low Temp. Phys. 38, 727 (2012).

${ }^{43}$ See supplementary material at http://dx.doi.org/10.1063/1.4894761 for details of the effects of site occupancy on the emission of $\mathrm{H}_{2} \mathrm{TAP}$ in $\mathrm{Ne}, \mathrm{Ar}$, and $\mathrm{N}_{2}$ hosts. 